\title{
Optimation of Depropanizer Unit using Turbo Expander and Its Controller using Model Predictive Control
}

\author{
Abdul Wahid ${ }^{1, *}$ and Ilham Maulana ${ }^{1}$ \\ ${ }^{1}$ Chemical Engineering Department, Universitas Indonesia, Depok, Indonesia
}

\begin{abstract}
In this study, Turbo expander (TE) and Model Predictive Control (MPC) is suggested for depropanizer unit to increase propane recovery and improve control performance of the unit. The model that used in the MPC is a first order plus dead time (FOPDT), which tested the control performance using set point (SP) and disturbance change test. The measurement of the performance is the integral of the absolute error (IAE). As a result, use of TE in the depropanizer able to increase the recovery of propane of $8.44 \%$ ( from $82.11 \%$ to $90.55 \%$ ). The control structure of the depropanizer unit using turbo expander are pressure control for the TE (using proportional-integral control), composition control in the distillate flow (using MPC), and pressure control in depropanizer column (using MPC). The control performance after carrying out the tests show that at the SP change, the composition control and the pressure control in depropanizer unit has lower IAE values for MPC than PI contoller. Similarly when tested using disturbance rejection, the IAE of MPC is lower than PI controller. It means that MPC is better than PI controller for composition control and pressure control in depropanizer unit.
\end{abstract}

\section{Introduction}

The increasing number of imports of Liquified Petroleum Gas (LPG) which became one of the government's attention because every year is always increasing. In 2013, Indonesia imported 3.3 million tons of LPG, estimated in 2017 to increase to 5 million tons or 51.51 percent increase from 2013 to 2017. In addition, the increase was also driven by increased public consumption, kerosene conversion to LPG in Eastern Indonesia, and the conversion of BBM to LPG for fishermen. In addition, LPG production also decreased resulting in a deficit [1]. To compensate for the increase in LPG needs new technologies are required in producing LPG, but it is very difficult to get it so that all that can be done is to optimize the existing technology. The technology used to produce LPG is using the NGL recovery process. The NGL recovery process has two methods namely the absorption method and the turbo-expander method. Turbo Expander is used to produce low temperatures with an expansion process on gas making low gas pressure. This is necessary to facilitate the separation to be carried out through depropanizer in improving propane recovery (Loïc, 2010). In addition, turbo expander also produces energy from pressure changes so that energy for hydrocarbon recovery process so that it can use the integrated energy from within the system [2]. In order for the process of separation to run optimum process control required. the purpose of process control is two, namely to reduce the changes that occur from a process due to interference and achieve the desired state when there is a change in operating conditions in the field. One of the commonly used process controls is the conventional feedback control system such as the Proportional-Integral (PI) control system [3]. In this research will be used predictive control model controller (MPC). The advantage of MPC over PI is its ability to optimize the process, both in current conditions, and in future conditions, while keeping the condition stable and anticipating and predicting the price of $\mathrm{CV}$ (controlled variable) and MV (manipulated variable) changes in operating conditions, so as to take appropriate control measures whereas PI does not have this anticipated capability. The controller uses the feedback control principle, so it is curative, waiting for a new error to act [4]. MPC has been widely used in several studies, namely research on process optimization on demethanizer using turbo-expander with MPC control [5], research on process optimization in deethanizer without using turboexpander with MPC controller [6], research on simulation process with MPC controller on depropanizer unit [7]. In this research will perform process optimization with MPC controller on depropanizer unit using turbo-expander.

\section{Methodology}

\subsection{Simulation environment}


The depropanizer unit used in this study is according to that used by Thanh [8]. However, in this study there are modifications to the system resulting in better performance in the recovery of propane with the addition of turbo expander.

To know the effect of addition of TE and process control on turbo expander is done with the following stages:

1. Process modelling under steady state conditions of the modeled system.

2. Determining operating conditions on the main unit of Depropanizer and turbo expander, feed conditions entering the system.

3. Changing the simulation to dynamic process and install the controllers. The system model in the simulation is converted into dynamic model which then each unit is installed control system that is MPC controller.

4. Identify the model system in identifying the model system, carried out the testing model, where the model testing is used PI Controller which will be impaired on PI Controller so obtained empirical modeling from the results of this testing model.

5. The simulation using MPC is carried out by entering the parameters obtained in the empirical modeling using first-order plus dead-time (FOPDT) model. The FOPDT parameters $(\mathrm{Kp}, \tau, \theta)$ are fed into the MPC controller.

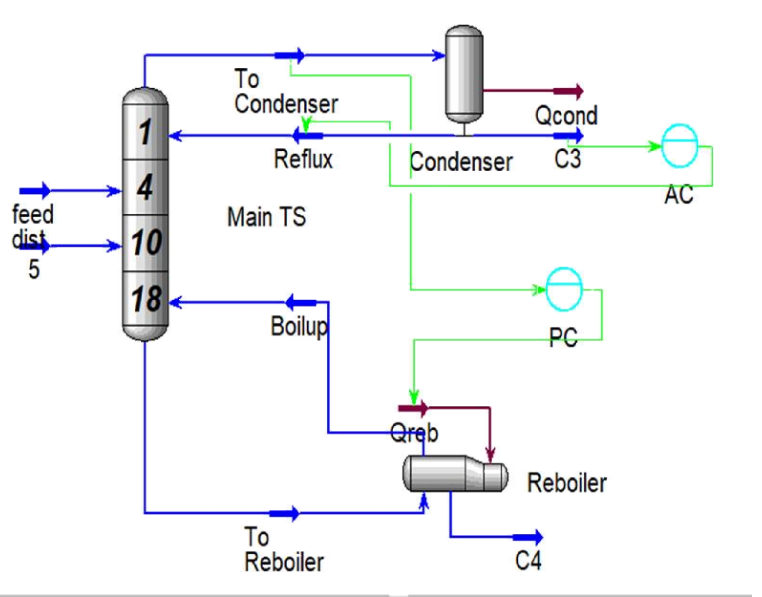

Figure 1 The control structure of Depropanzer with Turbo Expander

The design of the control on the depropanizer unit in the gas processing as a whole uses two control units (see Figure 1 and Table 1).

Table 1 Control Design of Depropanizer

\begin{tabular}{ccc}
\hline $\begin{array}{c}\text { Type } \\
\text { Controller }\end{array}$ & $\begin{array}{c}\text { Controlled } \\
\text { Variable }\end{array}$ & $\begin{array}{c}\text { Manipulated } \\
\text { Variable }\end{array}$ \\
\hline $\begin{array}{c}\text { Pressure } \\
\text { Control } \\
\text { (PC) }\end{array}$ & $\begin{array}{c}\text { pressure in } \\
\text { distillate }\end{array}$ & Reboiler duty \\
\hline $\begin{array}{c}\text { Composition } \\
\text { (AC) }\end{array}$ & $\begin{array}{c}\text { Component } \\
\text { Mole Fraction } \\
\text { of Propane in }\end{array}$ & Reflux flow \\
\hline
\end{tabular}

\section{C3 stream}

\subsection{Control Tuning}

Based on FOPDT model that is obtained from the PRC, controller tuning is done to get optimal control. Shridhar and Cooper [9] have developed the tuning method for MPC. However, if the controller performance that resulted is poor, the fine tuning is the best alternative method [10-13]. Three parameters of MPC have to tune are (sampling time), $\mathrm{P}$ (prediction horizon) and using identical model to compute $\mathrm{M}$ (control horizon).

\subsection{Controller Performance}

The performance of the controller is tested by doing setpoint tracking and disturbance rejection. The disturbances are the elevation of feed flow rate by $5 \%$ for composition control and the disturbance are the elevation of pressure of feed flow and set point tracking are changing the set point by 0.02 mole fraction( 0.88 to 0.9 ) for composition control and Set Point change by 0.4 barg (6.2 barg to 6.6 barg) for pressure control. Next is comparing the error value, IAE (integral absolute error), of the MPC and PI controllers to the set-point (SP) changes and also the disturbance to see which controller has more optimum performance. The smaller IAE values the better. The equation of IAE can be seen as follow:

$$
I A E=\int_{o}^{\infty}|S P(t)-C v(t)| d t
$$

\section{Results and discussion}

\subsection{Design of Depropanizer Unit using Turbo Expander}

Simulation design of depropanizer using turbo expander can be seen at Figure 2. In the simulation process of the depropanizer unit using turbo expander, the feed which is at once the output or output of the previous unit is deethanizer has a flow rate of $19,320 \mathrm{~kg} / \mathrm{h}$, with a temperature of $74^{\circ} \mathrm{C}$, and a pressure of $16 \mathrm{barg}$. The feed enters at separator to separate of vapor and liquid state of the feed. The vapor state enter the expander to reduce pressure of the vapor before entering depropanizer and the liquid state enter the cooler to reduce pressure to pretend the feed in the liquid state and then enter the depropanizer column.

The separation that occur in the depropanizer column at 6 barg in condenser and 7 barg in reboiler. After separation, distillate flow that in liquid state enter heater to make temperature increase until become vapor state and then enter booster to increase pressure because it's needed to reach LPG specification. The booster has supply power from expander. So that, energy is 
integrated within the system. The column specification design consists of 18 stages with internal column design using shieve-tray type. After use turbo expander in depropanizer unit can improve recovery propane by $8.44 \%$ and decrease reboiler duty by $21.49 \%$.

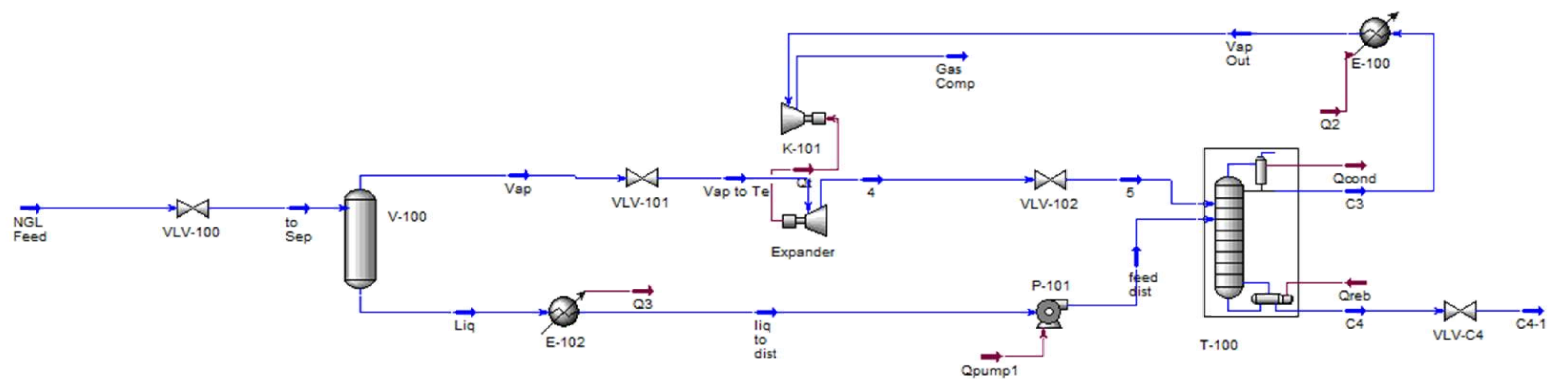

Figure 2. Simulation Design of Depropanizer Unit using Turbo Expander

\subsection{System Identification}

The main controlled variable $(\mathrm{CV})$ in depropanizer, generally, is the mole fraction on propane. Similarly, the depropanizer that use turbo expander, as the main $\mathrm{CV}$ is the mole fraction on propane. While the manipulated variable (MV) is the reflux flow rate. The FOPDT model, as the base controller tuning parameters a model used in the MPC, is determined using a process reaction curve (PRC) due to the change in reflux flow rate as shown in Figure 2.

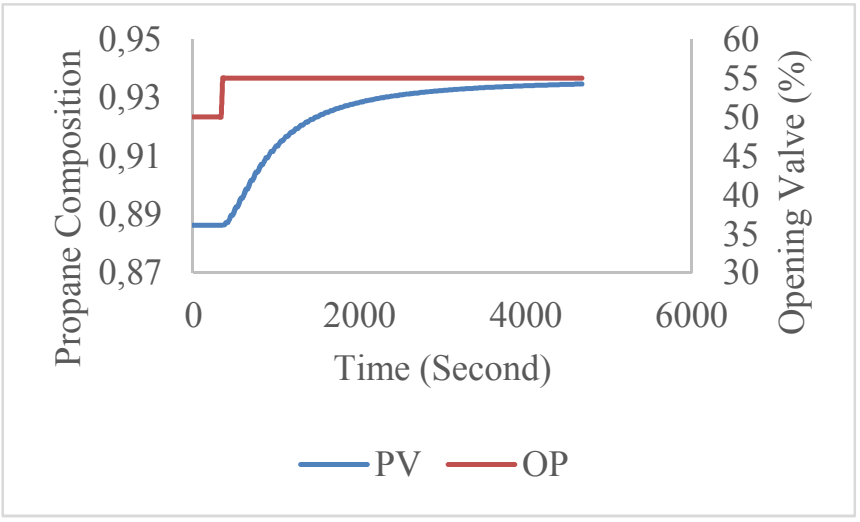

Figure 2 PRC for compostion control in depropanizer

Based on the PRC curve at Figure 2, it is obtained by valve opening to a change in the PV value (process variable) which indicates the interaction between the respective variables. The opening valve start form $50 \%$ and change with amplitude $10 \%$ become $55 \%$. The time of the test is adjusted until the respon stable. Then, based on the PRC curve can be obtained empirical modeling FOPDT process. The result of empirical modeling of FOPDT

$$
F O P D T=\frac{K p e^{-\theta s}}{\tau s+1}=\frac{0,00985 e^{-13,78 s}}{11,99 s+1}
$$

with time $(\tau)$ and dead time $(\theta)$ constants in minutes. A larger dead time indicates that the change response due to valve opening changes is slower. Then, the empirical value of process gain $(\mathrm{Kp})$, time constants $(\tau)$ and dead time $(\theta)$.

For the pressure control in depropanizer, FOPDT is obtained using PRC too. The PRC of pressure control can be seen at Figure 3.

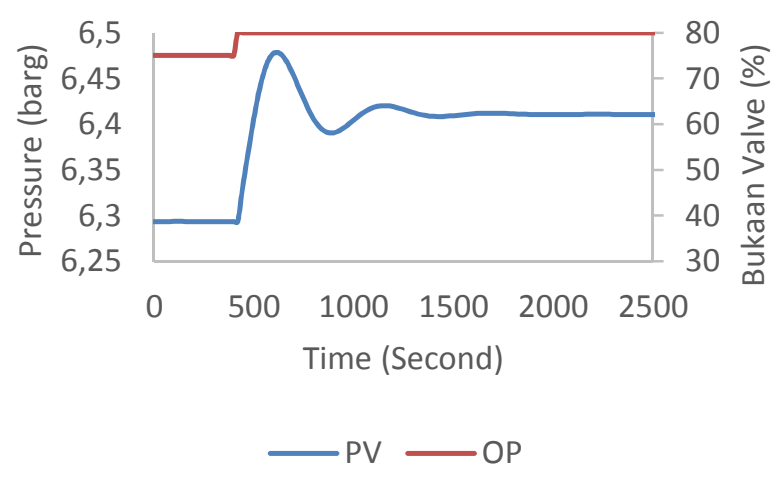

Figure 3 The PRC for pressure control in depropanizer

Based on Figure 3. The PRC of pressure control in the depropanizer has overshoot. It is mean the respond process has second orde. This control model has been approach using FOPDT or become first orde. In this PRC, valve was open from $75 \%$ to $80 \%$. Then based on the PRC, FOPDT model for pressure control can be seen at equation (3).

$$
\text { FOPDT }=\frac{K p e^{-\theta s}}{\tau s+1}=\frac{0,023 e^{-0,844 s}}{0,221 s+1}
$$

\subsection{MPC Tuning}

After getting FOPDT model of each control in the depropanizer. Parameters of pressure and composition controlling with MPC are tuned using the NonAdaptive DMC adjustment strategy developed by Shridhar and Cooper [9]. Meanwhile, the method of $\neg$ fine tuning is done repeatedly until the maximum tuning result is seen based on IAE value (Integral Absolute Error) which will be calculated later. But for PI controller, FOPDT is not used to tuning parameter of PI controller because PI controller using auto-tuning 
method that available in the UniSim. The parameter tuning of composition control can be seen at Table 2 .

Table 2. Tuning Parameter of Multivariable MPC for composition control

\begin{tabular}{cccc}
\hline Parameter & \multicolumn{3}{c}{ Tuning Method } \\
\cline { 2 - 4 } & $\begin{array}{c}\text { MPC } \\
\text { Fine- } \\
\text { Tunning }\end{array}$ & $\begin{array}{c}\text { Shidar } \\
\text { \& } \\
\text { Cooper }\end{array}$ & $\begin{array}{c}\text { Auto- } \\
\text { tuning } \\
\text { PI }\end{array}$ \\
\hline $\mathrm{P}$ & 25 & 63 & - \\
\hline $\mathrm{M}$ & 20 & 23 & - \\
\hline $\mathrm{T}$ & 1 & 1 & - \\
\hline $\mathrm{Kc}$ & - & - & 0.192 \\
\hline $\mathrm{Ti}$ & - & - & 7.9
\end{tabular}

And for the pressure control, parameter tuning can be seen at Table 3 .

Table 3. Tuning Parameter of Multivariable MPC for pressure control

\begin{tabular}{cccc}
\hline Parameter & \multicolumn{3}{c}{ Tuning Method } \\
\cline { 2 - 4 } & $\begin{array}{c}\text { MPC } \\
\text { Fine- } \\
\text { Tunning }\end{array}$ & $\begin{array}{c}\text { Shidar } \\
\& \\
\text { Cooper }\end{array}$ & $\begin{array}{c}\text { Auto- } \\
\text { tuning } \\
\text { PI }\end{array}$ \\
\hline $\mathrm{P}$ & 100 & 89 & - \\
\hline $\mathrm{M}$ & 49 & 49 & - \\
\hline $\mathrm{T}$ & 0.022 & 0.022 & - \\
\hline $\mathrm{Kc}$ & - & - & 0.247 \\
\hline $\mathrm{Ti}$ & - & - & 0.429 \\
\hline
\end{tabular}

\subsection{Set Point Change Test}

After obtaining each controller parameters through the methods above, tested the effect of set point change to be able to see the response of control result to controlling parameters of each controller that have been done tuning. The test of the effect of set point change is done on two controlled variables in depropanizer unit, ie pressure and composition. For composition, the set point is changed by increase composition of propane by $2.27 \%$. For pressure control, the set point is changed by increase the pressure depropanizer by $6.45 \%$ about 6.2 barg to 6.6 barg then observing the time required for the process variable to detect any change until it reaches the set point. Figures 4 shows the comparison of composition control response to a set point change of about 0.88 to 0.9 fraction mole of propane with each adjustment method.

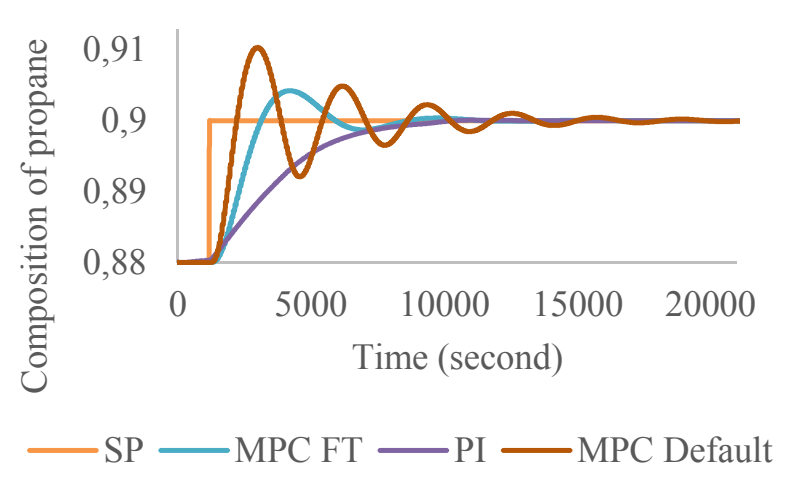

Figure 4. Composition Controller Response By Comparing Both Tuning Methods

Based on Figure 4, it can be seen that the tuning result with fine tuning method is also better when compared with the result of adjustment with PI controller using auto-tuning method. It is based on a faster (process variable) PV value to return to the set point set after the controller detects a change in the process by changing the set point by $5 \%$ of the initial value . Although at response of MPC controller using Fine-Tuning method has overshoot. Overshoot of MPC Fine-Tuning is still below of tolerance limitation of overshoot. The IAE value of each contoller can be seen at Table 4.

Table 4. The IAE calculation of composition control in depropanizer

\begin{tabular}{cccc}
\hline Parameter & \multicolumn{3}{c}{ Tuning Method } \\
\cline { 2 - 4 } & $\begin{array}{c}\text { Auto- } \\
\text { Tuning } \\
\text { PI }\end{array}$ & $\begin{array}{c}\text { MPC } \\
\text { Shidar } \\
\&\end{array}$ & $\begin{array}{c}\text { MPC } \\
\text { Fine- } \\
\text { Tunning } \\
\text { Cooper }\end{array}$ \\
\hline IAE & 1.664 & 2.377 & 1.637 \\
\hline Overshoot & - & $89.96 \%$ & $21.04 \%$ \\
\hline
\end{tabular}

Based on Table 4. The overshoot of MPC Fine Tuning is $21.04 \%$. This values is below the overshoot tolerance of $25 \%$. So it is applicable in this control. After calculation of IAE. The IAE value of MPC Fine Tuning is lower than IAE value of PI controller. it is mean the MPC Fine Tuning has better performance than PI control performance

Meanwhile, for pressure control, the set point is changed by raising the pressure by $6.45 \%$ from the pressure of feed and then also observed the time required for the process variable to detect and then respond to changes to reach the set point. Figures 5 shows the comparison of temperature control response to a $6.45 \%$ set point change with each adjustment method. 


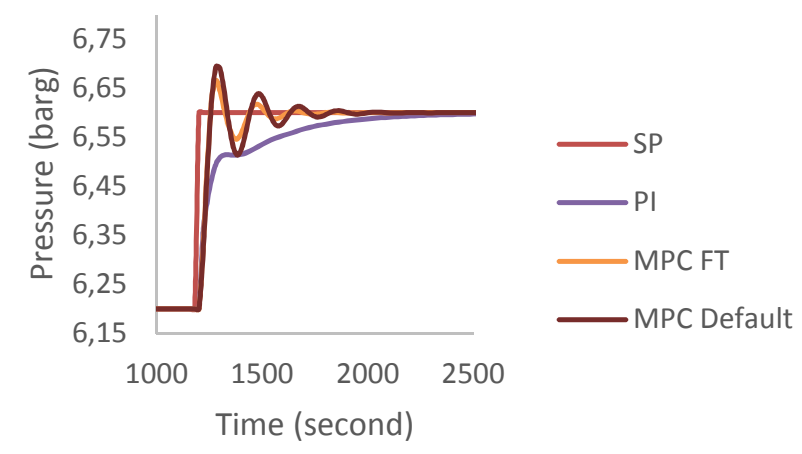

Figure 5. Pressure Controller Response By Comparing Tuning Methods

According to Fig. 5, it can be seen that the pressure control response which is the result of the tuning by the fine tuning method is also better when compared to the result of the PI controller using auto-tuning, similar to the result obtained in Figure 4 for composition control. It is based on a faster process temperature variable value to go back to the set point set after the controller responds to a change in the process by changing the set point by $6.45 \%$ of the initial value. In addition, using the constant result of tuning using the fine tuning method gives a faster response when compared to the adjustment constants with PI controller. Although the fine tuning method is dead time and also produces a larger overshoot, it can still be tolerated because the overshoot percentage is still below $15 \%$. In addition, it can be seen also in the fine tuning method has a faster rise time. It also supports the fact that the fine tuning method should be more appropriate to apply.

Another assessment to find out which method is better can be seen based on its IAE value. Table 5 shows the comparison of errors or errors result from each controller, both the pressure controller.

Table 5. Comparison of Error Values in Pressure Control

\begin{tabular}{cccc}
\hline Parameter & \multicolumn{3}{c}{ Tuning Method } \\
\cline { 2 - 4 } & $\begin{array}{c}\text { Auto- } \\
\text { Tuning } \\
\text { PI }\end{array}$ & $\begin{array}{c}\text { MPC } \\
\text { Shidar } \\
\& \\
\text { Cooper }\end{array}$ & $\begin{array}{c}\text { MPC } \\
\text { Fine- } \\
\text { Tunning }\end{array}$ \\
\hline IAE & 3.416 & 1.787 & 1.348 \\
\hline Overshoot & - & $38.39 \%$ & $12.91 \%$ \\
\hline
\end{tabular}

Based on Table 5, it can be seen that the IAE value of the fine tuning method is smaller when compared to the IAE value of the PI controller using auto-tuning method. With smaller IAE values. It is indicating that the control result with the fine tuning method is better than using the PI controller using auto-tuning method.

\subsection{Disturbance Change Test}

As well as set point change test, after obtained parameter tuning of each controller. tested the effect of given disturbance to be able to see the response of control result to controlling parameters of each controller that have been done tuning. The test of the effect of given disturbance is done on two controlled variables in depropanizer unit, ie pressure and composition. For composition, the given disturbance by increase feed flow by $5 \%$. For pressure control, the set point is changed by increase the pressure by $2.5 \%$ from the feed pressure and then observing the time required for the process variable to detect any change until it reaches the set point. Figures 6 shows the comparison of composition control response to given disturbance.

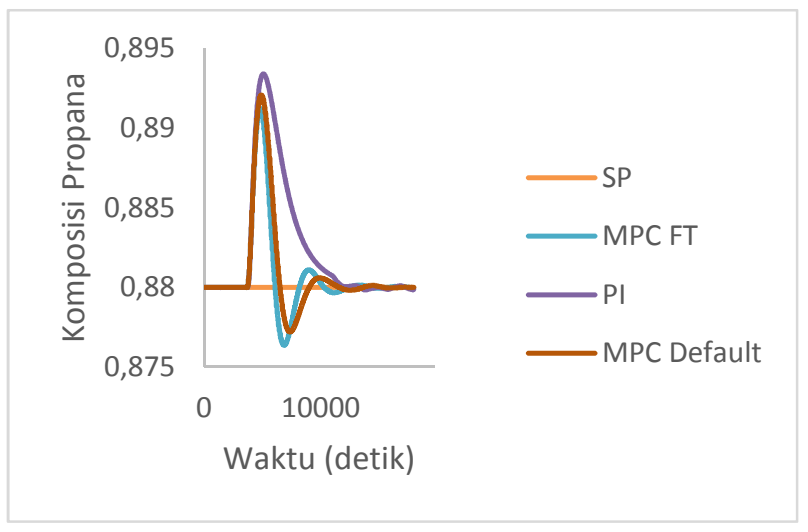

Figure 6. Composition Controller Response By Comparing Tuning Methods after given disturbance

According of Figure 6, it can be seen that response of PI controller after given dusturbance has highest overshoot than the MPC. it is mean the PV has become over and take longer time to get stable or reach set point. As well as the pressure control after given disturbance test, the response of the pressure control can be seen at Figure 7.

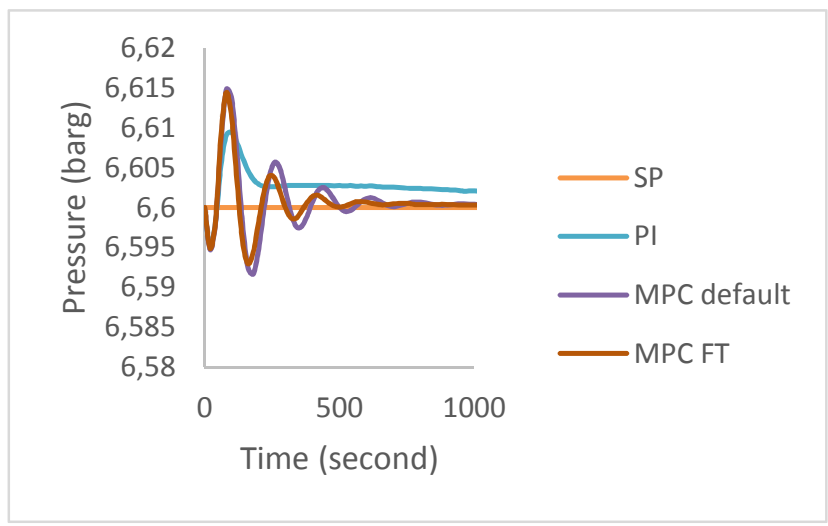

Figure 7. Pressure Controller response by comparing tuning method after given disturbance.

Based on Figure 7, response of MPC has higher overshoot than response of PI controller response after given disturbance. But, PI controller response need more time to stable or reach set point if its compared by 
response of MPC controller although it has overshoot can fast to be stable or reach set point. to know about who the better performance of each controller, IAE

Table 6. The result of IAE value for each controller

\begin{tabular}{|c|c|c|c|c|}
\hline \multirow[t]{2}{*}{ Controller } & \multirow[t]{2}{*}{ Parameter } & \multicolumn{3}{|c|}{ Tuning Method } \\
\hline & & $\begin{array}{c}\text { Auto- } \\
\text { Tuning } \\
\text { PI }\end{array}$ & $\begin{array}{c}\text { MPC } \\
\text { Shidar } \\
\& \\
\text { Cooper }\end{array}$ & $\begin{array}{c}\text { MPC } \\
\text { Fine- } \\
\text { Tuning }\end{array}$ \\
\hline Composition & IAE & 2.139 & 1.106 & 1.237 \\
\hline Pressure & & 0.284 & 0.113 & 0.139 \\
\hline
\end{tabular}

Based on Table 6, it can be seen that MPC Fine-Tuning has the lower IAE compared by PI controller IAE at both controller. the lower IAE value means the better performance of the controller.

\section{Conclusions}

Based on the results from this study, the following conclusions have been drawn:

- In the depropanizer unit using turbo expander can improve recovery of propane by $8.44 \%$ and decrease reboiler duty by $21.49 \%$.

- Control system applied to the depropanize unit using turbo expander in this study is composition controller and pressure control in depropanizer unit

- Fine Tuning method is better than method developed by Shridhar and Cooper (1998) for the MPC control of the depropanizer using, characterized by smaller IAE values.

- The MPC control using Fine-Tuning method has better performance compared by PI control using auto-tuning method.

We express our gratitude to the Universitas Indonesia which has funded this research through the scheme of Hibah Publikasi Internasional Terindeks untuk Tugas Akhir Mahasiswa (PITTA) No.2358/UN2.R3.1/HKP.05.00/2018.

\section{References}

1. Ahmad A. and Wahid A 2007 Application of model predictive control (MPC) tuning strategy in multivariable control of distillation column. Reaktor 11(2) 66-70

2. Astr“om, K.J., H“"agglund, T., Hang, C.C., and Ho, W.K. (1993). Automatic tuning and adaptation for PID controllers - a survey. Cont. Eng. Practice, 1, 699-714. Kano M and Ogawa M 2010 The state of the art in chemichal process control in Japan: Good practice and questionnaire survey $J$. Process Contr. 20 969-82.. value calculation is needed. The result of IAE value calculation can bee seen at Table 6 .

3. Beall, James. 2010. Multivariable Model Predictive Controller Improves Turbo Expander Demethanizer Column Performance. Emerson Process Managemen

4. Camacho, E. F. and Bordons, C.1999. Model Predictive Control in Process Industry. London: Springer-Verlag

5. Li, Yajun et al.2017. System Optimization of Turboexpander Process for Natural Gas Liquid Recovery. CHERD 2703: S02638762(17)30320-9

6. Marlin, T. (2000). Process Control: Designing Processes and Control Systems for Dynamic Performance. United States: McGraw-Hill Higher Education.

7. Pebrianto.2017. Impor LPG meningkat pada tahun 2017, [online], http://bisnis.liputan6.com/read/2829523/impor elpiji-meingkat-pada-2017 accessed at Dec 5, 2017

8. Thanh Tuan. 2016. Control the propanizer in dynamic hysys simulation using MPC in Simulinkmatlab. Procedia engineering. 10.1016

9. Shridhar, R., \& Cooper, D. J. (1998). A Tuning Startegy for Unconstrained Multivariable Model Predictive Control. Control Engineering Practice, 37, 4003 4016.

10. Skogestad, S. (2004). Control Structure design for Complete Chemical Plants. Journal of Computer and Chemical Engineering, 28, 219-234.

11. A Wahid and A P Prasetyo. A Comparative study between MPC and PI controller to control vacuum distillation unit for producing LVGO, MVGO, and HVGO. IOP Conf. Series: Materials Science and Engineering 334 (2018) 012020

12. A Wahid and I G E P Putra. Multivariable Model Predictive Control Design of Reactive Distillation Column for Dimethyl Ether Production. IOP Conf. Series: Materials Science and Engineering 334 (2018) 012018

13. A Wahid and F F Adicandra. Optimization Control of LNG Regasification Plant using Model Predictive Control. IOP Conf. Series: Materials Science and Engineering 334 (2018) 012022 